\title{
Hygroscopic properties of ultrafine aerosol particles in the boreal forest: diurnal variation, solubility and the influence of sulfuric acid
}

\author{
M. Ehn ${ }^{1}$, T. Petäjä ${ }^{1}$, H. Aufmhoff ${ }^{2}$, P. Aalto ${ }^{1}$, K. Hämeri ${ }^{1,3}$, F. Arnold ${ }^{2}$, A. Laaksonen ${ }^{4,5}$, and M. Kulmala ${ }^{1}$ \\ ${ }^{1}$ Division of Atmospheric Sciences, Department of Physical Sciences, P.O. Box 64, 00014 University of Helsinki, Finland \\ ${ }^{2}$ Max-Planck Institute for Nuclear Physics (MPIK), Atmospheric Physics Division, P.O. Box 103980, 69029 Heidelberg, \\ Germany \\ ${ }^{3}$ Finnish Institute of Occupational Health, Topeliuksenkatu 41 a A, 00250 Helsinki, Finland \\ ${ }^{4}$ Department of Applied Physics, University of Kuopio, P.O. Box 1627, 70211 Kuopio, Finland \\ ${ }^{5}$ Finnish Meteorological Institute, P.O. Box 503, 00101 Helsinki, Finland
}

Received: 19 September 2006 - Published in Atmos. Chem. Phys. Discuss.: 10 October 2006

Revised: 10 January 2007 - Accepted: 10 January 2007 - Published: 16 January 2007

\begin{abstract}
The hygroscopic growth of aerosol particles present in a boreal forest was measured at a relative humidity of $88 \%$. Simultaneously the gas phase concentration of sulfuric acid, a very hygroscopic compound, was monitored. The focus was mainly on days with new particle formation by nucleation. The measured hygroscopic growth factors (GF) correlated positively with the gaseous phase sulfuric acid concentrations. The smaller the particles, the stronger the correlation, with $r=0.20$ for $50 \mathrm{~nm}$ and $r=0.50$ for $10 \mathrm{~nm}$ particles. The increase in GF due to condensing sulfuric acid is expected to be larger for particles with initially smaller masses. During new particle formation, the changes in solubility of the new particles were calculated during their growth to Aitken mode sizes. As the modal diameter increased, the solubility of the particles decreased. This indicated that the initial particle growth was due to more hygroscopic compounds, whereas the later growth during the evening and night was mainly caused by less hygroscopic or even hydrophobic compounds. For all the measured sizes, a diurnal variation in GF was observed both during days with and without particle formation. The GF was lowest at around midnight, with a mean value of 1.12-1.24 depending on particle size and if new particle formation occurred during the day, and increased to 1.25-1.34 around noon. This can be tentatively explained by day- and nighttime gas-phase chemistry; different vapors will be present depending on the time of day, and through condensation these compounds will alter the hygroscopic properties of the particles in different ways.
\end{abstract}

Correspondence to: $\mathrm{M}$. Ehn

(mikael.ehn@helsinki.fi)

\section{Introduction}

Recent studies have shown that formation of new particles occurs frequently in the atmosphere (Kulmala et al., 2004). These particles form through nucleation and grow further by coagulation and condensation. Understanding this entire process has been a major goal in the field of aerosol physics for a long time. Sometimes newly formed particles grow to sizes that are relevant for scattering light or acting as cloud condensation nuclei. Due to the ubiquitous presence of particles formed via atmospheric nucleation, they are likely to be important in climate and air pollution issues.

In order to quantitatively understand the formation and growth of new particles in the atmosphere, the chemical composition of individual particles of about $1 \mathrm{~nm}$ and larger should be determined. However, determination of the composition of the smallest particles $(<20 \mathrm{~nm})$ remains tedious due to the small masses involved. The first direct measurements of the composition have been reported during recent years (Smith et al., 2004, 2005), using mass spectrometry. Characterization studies of sub- $20 \mathrm{~nm}$ particles have, however, more frequently utilized indirect measurement methods such as determination of particle volatility or hygroscopicity (Petäjä et al., 2006; Wehner et al., 2005; Sakurai et al., 2005; Väkevä et al., 2002).

Early observations of new particle formation were made in a boreal forest research station in southern Finland (Mäkelä et al., 1997). The continuous particle size distribution measurements now cover about 10 years of atmospheric particle formation events. However, one of the open questions is still the exact composition and formation mechanism of freshly nucleated particles. One of the early attempts to study the composition of these particles in the boreal forest was done

Published by Copernicus GmbH on behalf of the European Geosciences Union. 


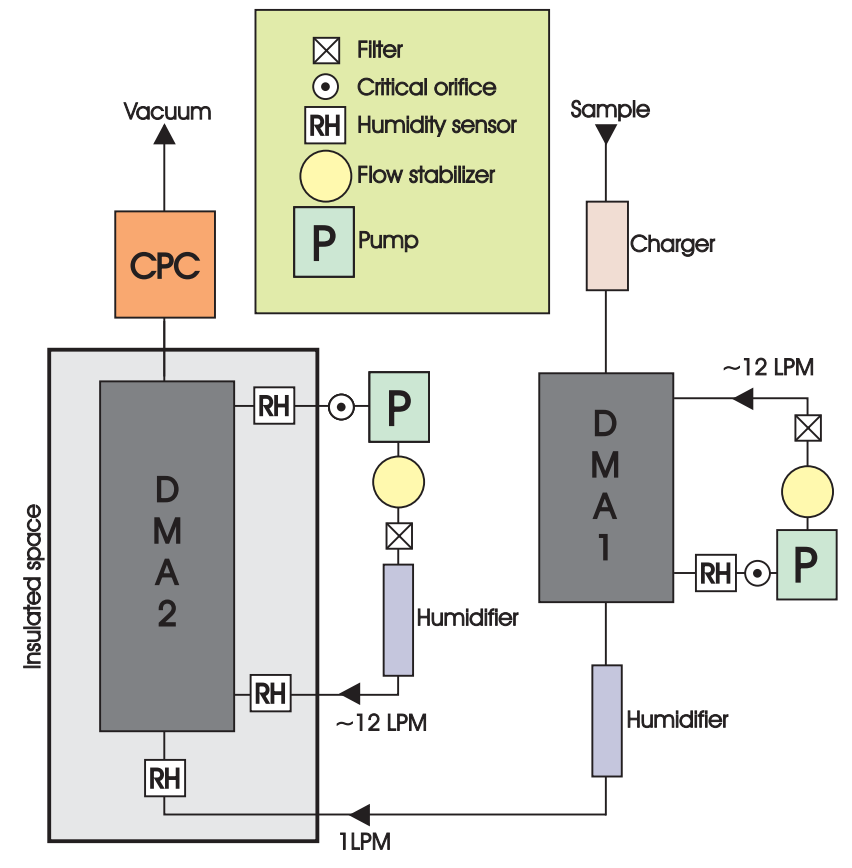

Fig. 1. Schematic diagram of the HTDMA.

by Hämeri et al. (2001). They measured the hygroscopicity of nucleation, Aitken and accumulation mode particles and observed a clear diurnal variation during days with particle formation. Hygroscopic growth was high during daytime and lower during nighttime. This behavior was most prominent for the smaller particle sizes, but could also be discerned for accumulation mode particles. In addition, they observed that the nighttime minimum was lower before days with new particle formation compared to days without nucleation. Differences in condensable vapor concentrations and properties were deemed to be the reason for both observations.

In this study we present focused measurements of the hygroscopicity of nucleation and Aitken mode aerosol particles together with atmospheric sulfuric acid concentrations using a Hygroscopicity Tandem Differential Mobility Analyzer (HTDMA) and a Chemical Ionization Mass Spectrometer (CIMS). The measurements were conducted in a boreal forest area in Southern Finland during April and May 2005. The diurnal variation during days with and without new particle formation was analyzed. In addition, the influence of gaseous sulfuric acid on particle hygroscopicity was determined. Finally, the evolution of the solubility of newly formed particles was studied during their growth in order to determine changes in condensing vapor properties.

\section{Experimental setup}

Measurements were conducted at SMEAR II (Station for measuring Forest Ecosystem-Atmosphere Relations) located in Hyytiälä, Southern Finland. The site is surrounded by 40- year-old pine forest (Pinus Sylvestris L.). The aerosol instrumentation used in this study was located in a small, airconditioned cottage and the CIMS in a measurement container nearby. Due to the installation of many new instruments in the cottage for the campaign, the temperature at times fluctuated up to $3^{\circ} \mathrm{C}$ during one day. The set point temperature was between $21^{\circ} \mathrm{C}$ and $24^{\circ} \mathrm{C}$. Detailed information about the continuous measurements and the infrastructure can be found elsewhere (Vesala et al., 1998; Kulmala et al., 2001b). This study was conducted as a part of the BACCI/QUEST-campaign.

\subsection{Aerosol instrumentation}

\subsubsection{Hygroscopicity}

A HTDMA (Rader and McMurry, 1986) was used to measure hygroscopicity of selected nucleation and Aitken mode particle sizes. The growth was monitored at $88 \%$ for 10,20 , 30 and $50 \mathrm{~nm}$ particles. A growth spectrum was measured in just below $10 \mathrm{~min}$, resulting in one growth measurement for each dry size roughly every $40 \mathrm{~min}$.

The working principle of the HTDMA is described below, and a schematic diagram of the instrument is shown in Fig. 1. The sample we wish to study is passed through a charger where the molecules in the air are ionized by a radioactive source $(\mathrm{Ni}-63 ; 370 \mathrm{MBq})$ and interact with the particles, bringing them to a equilibrium charge distribution before they enter the Differential Mobility Analyzer (DMA). A DMA (Winklmayr et al., 1991) classifies particles based on their electrical mobility and is used to select a narrow size range from the polydisperse sample. The sheath air coming into the first DMA (10.9 cm long, denoted DMA1) is dried and therefore possible water in the particles evaporates very quickly once it enters the DMA. During the measurement period, the ambient temperature fluctuated between $-7^{\circ} \mathrm{C}$ and $+16^{\circ} \mathrm{C}$, leading to a partial drying of the sample already when entering the warmer cottage. The dew point temperature measured at the SMEAR station, varied between $-15^{\circ} \mathrm{C}$ and $+9^{\circ} \mathrm{C}$, staying between $-5^{\circ} \mathrm{C}$ and $+5^{\circ} \mathrm{C}$ the majority of the time. This resulted in a maximum $\mathrm{RH}$ of $40 \%$ entering DMA1, with the mean value closer to $20 \%$. The DMA1 excess flow RH was around 3\% when the silica gel in the flow stabilizer had recently been changed, and grew to a maximum of $14 \%$ before the silica gel was changed again. The time for particles of the measured sizes to reach equilibrium with the surrounding water vapor is less than one millisecond (Kerminen, 1997). After DMA1 we have a dry, largely monodisperse aerosol of a selected size (referred to as the dry size). We then pre-humidify the aerosol to a chosen relative humidity (RH), usually between 70 and $85 \%$. The particles enter the second DMA ( $28 \mathrm{~cm}$ long, denoted DMA2) and come in contact with the humidified sheath air and reach their final humidity. At this point some of the particles may have absorbed water from the surrounding water vapor and grown 
to larger sizes. The humidified size distribution is scanned by counting the number of particles of different sizes passing through DMA2 to the TSI 3010 condensation particle counter (CPC, McMurry, 2000). The final particle size distribution depends on the chemical composition of the selected particles.

The humidifiers consist of $6 \mathrm{~mm}$ stainless steel tube that has been cut and separated for up to $3 \mathrm{~cm}$. This part has been replaced by a GoreTex-membrane, and the tubing is surrounded by liquid water. The sample flow passes through the tubing and is humidified by water vapor diffusing through the GoreTex-membrane. The amount of diffusing water vapor can be controlled by controlling the temperature of the water. The aerosol flow into, and the excess flow out of, DMA2 are RH-controlled. Both RHs are measured by Vaisala HMP143A humidity probes. Similarly, the RH in the sheath flow into DMA2 is measured by a HMP143A, and the excess flow out of DMA1 with a Vaisala Humitter 50Y to ensure sufficient drying of the sample flow. In the excess flow line out of DMA2, a General Eastern Hygro M4 dewpoint sensor is also operated. The uncertainties stated by the manufacturers are $\pm 3 \% \mathrm{RH}$ and $\pm 1.25 \%$ for the HMP143 and M4, respectively.

Both DMAs have closed loop arrangements (Jokinen and Mäkelä, 1997), meaning that the excess flows are filtered and reused in the sheath flow. This removes the need for pressurized air and vacuum, which might not always be available during field measurements. As the humid excess air of DMA2 is recirculated, the sheath air humidifier only adds a small amount of water vapor to the flow, thereby decreasing the water consumption of the system significantly. The critical orifices keep the flows very stable and no mass flow controllers are needed. Flow stabilizers ( 51 plastic bottles) are used to remove the flow oscillations generated by the pumps. In the DMA1-loop the bottle is filled with silica gel to keep the flow dry, and in the DMA2-loop it is filled with glass marbles $(\mathrm{d}=7 \mathrm{~mm})$.

Critical orifices controlled the flows, which were measured each day. In the case of a change in one of the sheath flows, the new values were fed into the program. Both flows were close to 12 LPM and fairly stable. The aerosol/sample flow was 1 LPM. Calibration measurements with ammonium sulfate were performed daily.

\subsubsection{Aerosol size distribution}

The particle number size distribution from 3 to $1000 \mathrm{~nm}$ was measured with a twin Differential Mobility Particle Sizer (DMPS) that has been used for continuous measurements in Hyytiälä since 1996 (Aalto et al., 2001). The twin-DMPS consists of two separate DMPS-systems measuring in parallel. The first one is optimized for small particles and has a short $(10.9 \mathrm{~cm})$ DMA with high flowrate and a TSI 3025 CPC. The second system has a medium-sized $(28.0 \mathrm{~cm})$ DMA and a TSI 3010 CPC for better counting statistics.
The first system measures dry particle sizes between 3 and $40 \mathrm{~nm} \mathrm{~s}$ and the second between 10 and $1000 \mathrm{~nm}$.

\subsection{Gaseous phase measurements}

The Max Planck Institute for Nuclear Physics in Heidelberg, Germany, measured the number concentration of gaseous sulfuric acid $\left(\mathrm{H}_{2} \mathrm{SO}_{4}\right)$ with a mass spectrometer.

The Quadrupole Ion Trap (QIT)-CIMS measures ultratrace gases with sub-pptv concentrations. A radioactive Po-210 ion source produces the reagent ions $\mathrm{NO}_{3}^{-}$and $\mathrm{NO}_{3}^{-}\left(\mathrm{HNO}_{3}\right)$ from $\mathrm{NO}_{2}$ and $\mathrm{HNO}_{3}$. These ions react with $\mathrm{H}_{2} \mathrm{SO}_{4}$ in a flow-tube reactor at ambient pressure forming $\mathrm{HSO}_{4}^{-}$and $\mathrm{HSO}_{4}^{-}\left(\mathrm{HNO}_{3}\right)$ with rate coefficients close to the ion-molecule collision rate coefficients. Finally, an ion trap mass spectrometer is used to detect and identify the ions. Careful calibrations were performed using a $\mathrm{H}_{2} \mathrm{SO}_{4}$ source based on water vapor photolysis. The detection limit of $\mathrm{H}_{2} \mathrm{SO}_{4}$ is as low as $2 \times 10^{5} \mathrm{~cm}^{-3}$ corresponding to an atmospheric mole fraction of 8 ppqv. The time resolution of the $\mathrm{H}_{2} \mathrm{SO}_{4}$ measurements is better than $10 \mathrm{~s}$, but usually the $\mathrm{H}_{2} \mathrm{SO}_{4}$ concentrations were integrated over $200 \mathrm{~s}$ to reduce statistical error. The absolute uncertainty is $\pm 30 \%$. For more details, see Aufmhoff et al. (2007) ${ }^{1}$.

\section{Data analysis}

The particle dry sizes measured were 10, 20, 30 and $50 \mathrm{~nm}$. Statistically sufficient concentrations of $10 \mathrm{~nm}$ particles were only observed during new particle formation, and therefore this data is not used in all calculations. A lower limit for the total concentration during each measurement was set for the larger particle sizes as well. The final RH value assigned to a scan was the average of the two sensors in the excess flow of DMA2. Measurements that deviated more than one percentage point from the setpoint of $88 \%$ were discarded.

\subsection{Hygroscopicity}

The humidified spectra measured with the HTDMA were inverted by taking into account the transfer function of DMA2 in accordance with Stolzenburg (1988). The humidified spectra measured by the HTDMA were almost without exception monomodal. At times the spectrum showed a broadening that might imply external mixing, and during a few periods a small fraction of the particles formed a separate mode. These occasions were, however, so rare that the entire dataset was analyzed as if there was only one type of particles in the air. External mixing is usually more important for

\footnotetext{
${ }^{1}$ Aufmhoff, H., Hanke, M., and Arnold, F.: Atmospheric measurements of gaseous sulfuric acid: Deployment of a novel ion trap CIMS instrument, in preparation, 2007.
} 
larger particle sizes (Hämeri et al., 2001). The values used in the analysis were the diameter growth factors

$\mathrm{GF}=\frac{\text { mean humidified diameter }}{\text { mean dry diameter }}$.

Each measurement was therefore described by a single value, the GF. Before the campaign began, we conducted measurements without any humidification in DMA2. The deviation from GF 1.00 was between 3 and 4\% depending on the dry size, and these values were incorporated into the mean dry diameter in Eq. (1).

Determination of the correct RH inside DMA2 was the most significant source of uncertainty in the measurements. We are not able to measure the temperature inside the DMA, and therefore we could not determine the precise relative humidity. A deviation of 0.2 degrees between the DMA and the measurement probe in the excess flow would lead to an error of 1 percentage point in RH. The uncertainty of the measurements was estimated to a change in GF of \pm 0.05 .

\subsection{Particle soluble mass fractions}

A simplified two-component model was applied to the hygroscopic data as suggested by Swietlicki et al. (1999). The model assumes that a particle consists of a hydrophobic component that is insoluble, and a soluble compound that absorbs water independently of the inert component. This gave us a soluble mass fraction, which in this paper will simply be denoted by the soluble fraction. Assuming further that the soluble compound was ammonium sulfate $\left(\left(\mathrm{NH}_{4}\right)_{2} \mathrm{SO}_{4}\right)$, we were able to calculate the fraction of soluble material in the particles. The hygroscopic behavior of ammonium sulfate is known fairly accurately due to many experimental and theoretical studies on the thermodynamics of water - ammonium sulfate particles. The soluble fraction $\epsilon$ is therefore given by

$\epsilon=\frac{\mathrm{GF}_{\mathrm{amb}}^{3}-1}{\mathrm{GF}_{\mathrm{AS}}^{3}\left(D_{p}\right)-1}$,

where $\mathrm{GF}_{\mathrm{amb}}$ is the measured GF of the particle and $\mathrm{GF}_{\mathrm{AS}}$ is the GF of a pure ammonium sulfate particle that has grown to the size of the measured particle $\left(D_{p}\right)$. In our calculations of the GF of water-ammonium sulfate particles, we have used the polynomial fit for the molality from Potukuchi and Wexler (1995) and the density fit from Tang and Munkelwitz (1994). When calculating the Kelvin effect we have used the surface tension fit by Korhonen et al. (1998). This twocomponent model was used to investigate the change in soluble fractions of recently formed particles during their growth.

If the mean RH during a measurement was not exactly at the setpoint, the GF was scaled to this value by using the above mentioned model: the soluble fraction was calculated at the measured RH, and thereafter the growth factor at the setpoint-RH was evaluated.

The twin-DMPS system measured the time evolution of the size distribution. Based on this data, days were selected keeping in mind several criteria: new particle formation was detected and the particles formed a clear mode, the particles grew without distinct interruptions due to the change of air mass, and concurrent hygroscopicity measurements were available.

To characterize the temporal evolution of the mode of new particles, log-normal distributions were fitted to the DMPS data (Hussein et al., 2005) to obtain the position, width and size of the mode of new particles. The position was expressed as the geometric mean diameter (GMD) and the width by the standard deviation $(\sigma)$. This gave us a measure of the distance between the GMD of new particles and the dry size ( $\left.D_{p \text {,dry }}\right)$ measured by the HTDMA through

$\Delta \sigma=\frac{\log \left(D_{p, \text { dry }}\right)-\log (\mathrm{GMD})}{\log (\sigma)}$.

When a HTDMA measurement was made within 5 min of a DMPS scan, and the difference between GMD and dry size was less than one standard deviation $(|\Delta \sigma|<1)$, the soluble fraction was calculated. In this way we made sure that we were measuring particles close to the maximum of the mode.

This two-component model can also be used to determine the amount of insoluble and soluble gases condensing onto the particles and causing them to grow (Kulmala et al., 2001a). When we know the soluble fractions at two different sizes, we can calculate the ratio of insoluble to soluble mass flux (denoted $I_{1}$ and $I_{2}$, respectively) onto the particles. This gives an indication of the change in condensing vapors during the different stages of the growth.

We wish to stress that the use of the soluble fraction in this study gave us the possibility to analyze the hygroscopicity of the particles independently of differences in size. The calculations of the soluble fractions are based on many assumptions, and should therefore not be thought of as absolute values, but rather as values comparable to each other.

\section{Results and discussion}

HTDMA measurements were conducted 1 April through 18 May 2005. During this time new particle formation events were observed during 1, 3-6, 12-14, 16-20, 24-27, 30 April and 2, 3, 7, 11-14, 16 May. Henceforth, these days will be referred to as "event days". An example of an event day is plotted in Fig. 2, presenting the size distribution and particle number concentration measured by the DMPS, gaseous sulfuric acid concentration measured by the CIMS, and the solar (global) radiation measured at a height of $18 \mathrm{~m}$ with a Astrodata Reemann TP3 pyranometer.

\subsection{Diurnal variation of hygroscopicity}

During the campaign the growth factors varied from day to day, but a clear diurnal cycle was present during a single day, namely higher growth factors during daytime than nighttime. This phenomenon had been observed previously in 

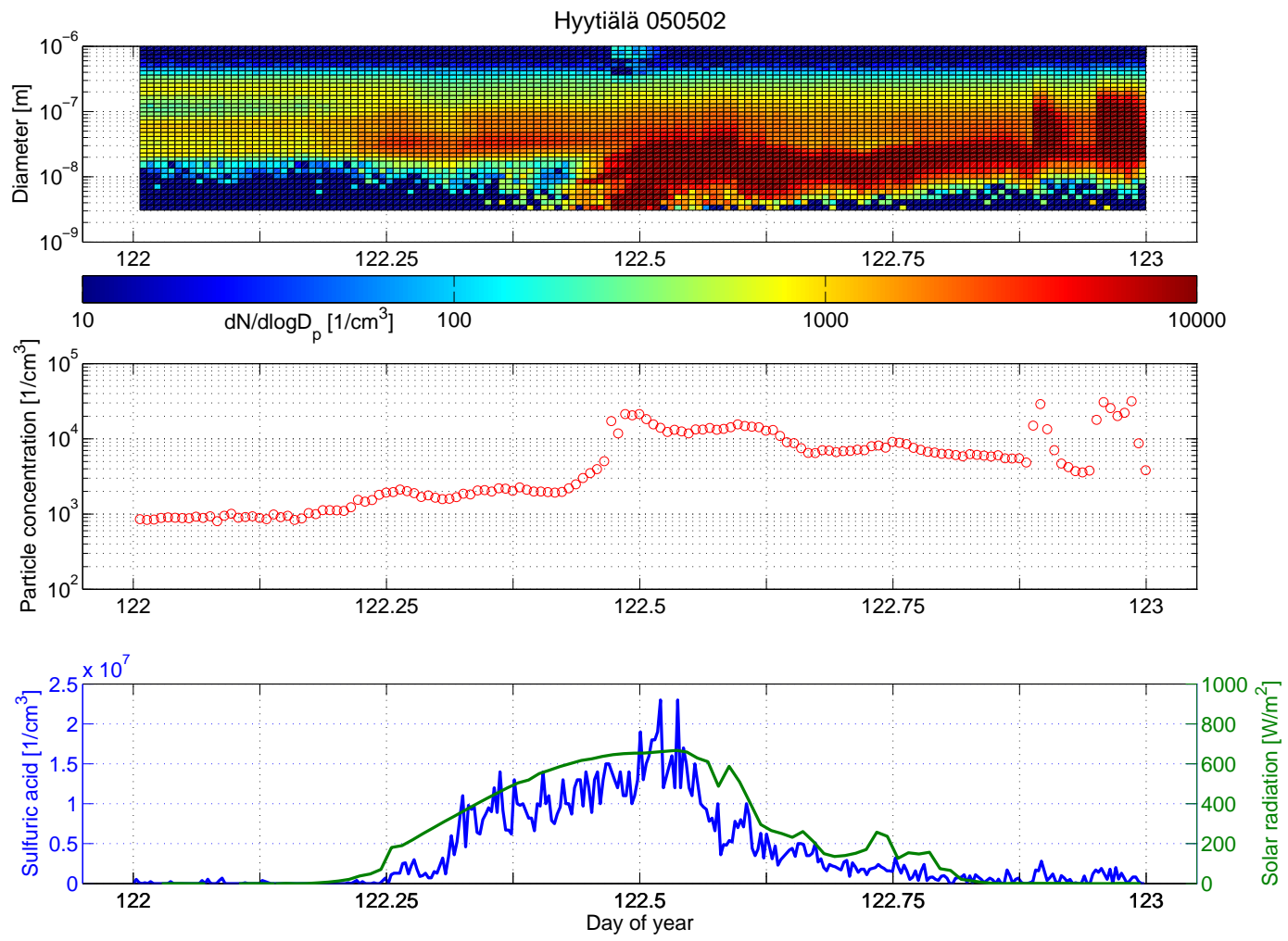

Fig. 2. Size distribution and sulphuric acid data for 2 May 2005. A burst of new particles is detected before noon (top panel), increasing the total particle concentration by an order of magnitude (middle panel). The bottom figure depicts the solar radiation and gaseous sulfuric acid concentration, both following a very similar pattern, peaking just after noon.

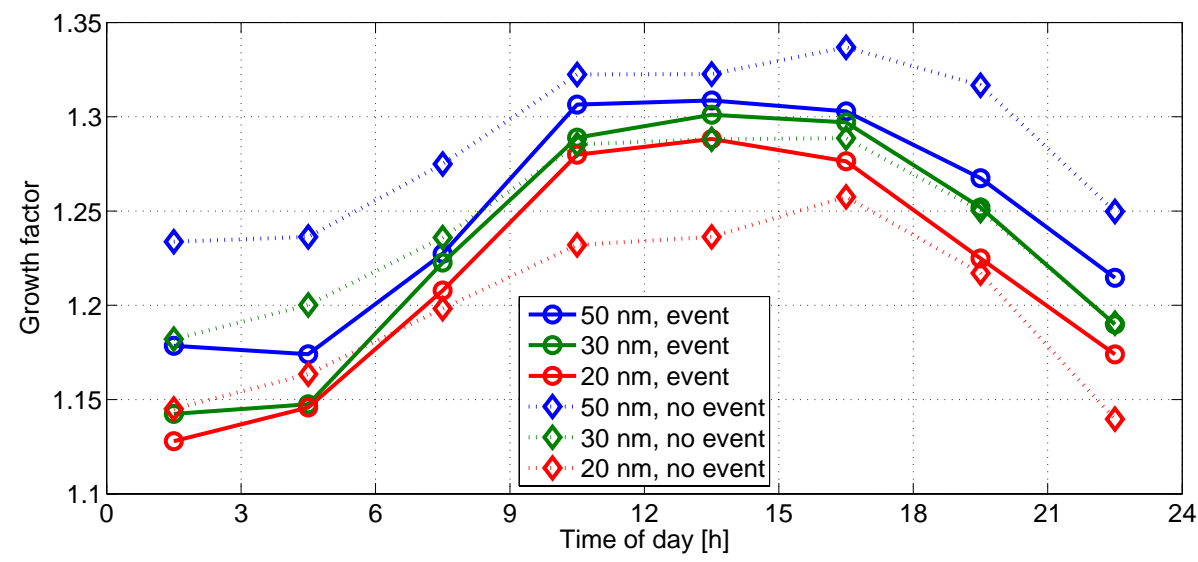

Fig. 3. Diurnal variation of the growth factors for 20,30 and $50 \mathrm{~nm}$ particles. The data is averaged over $3 \mathrm{~h}$ periods. The solid and dashed lines correspond to event days and non-event days respectively. Event days are always preceded by nights with lower growth factors.

Hyytiälä by Hämeri et al. (2001) during event days. Their study showed that the effect was strongest for ultrafine particles, but could also be observed for larger particles.

We divided the measurements between days with and without events and averaged the hygroscopicity data over three-hour periods sacrificing some resolution for better statistics. Figure 3 shows the results for 20, 30 and $50 \mathrm{~nm}$ particles. There was an average increase in the growth fac- tors of about 0.1 during non-event days and about 0.15 during event days compared to the corresponding nighttime values. A diurnal variation could, in other words, be detected both during days with, and days without particle formation. This diurnal variation could result from the different atmospheric conditions during day and night. For example $\mathrm{H}_{2} \mathrm{SO}_{4}$, which has a high water vapor affinity, correlates with global radiation (Fig. 2) and usually reaches maximum gas-phase 

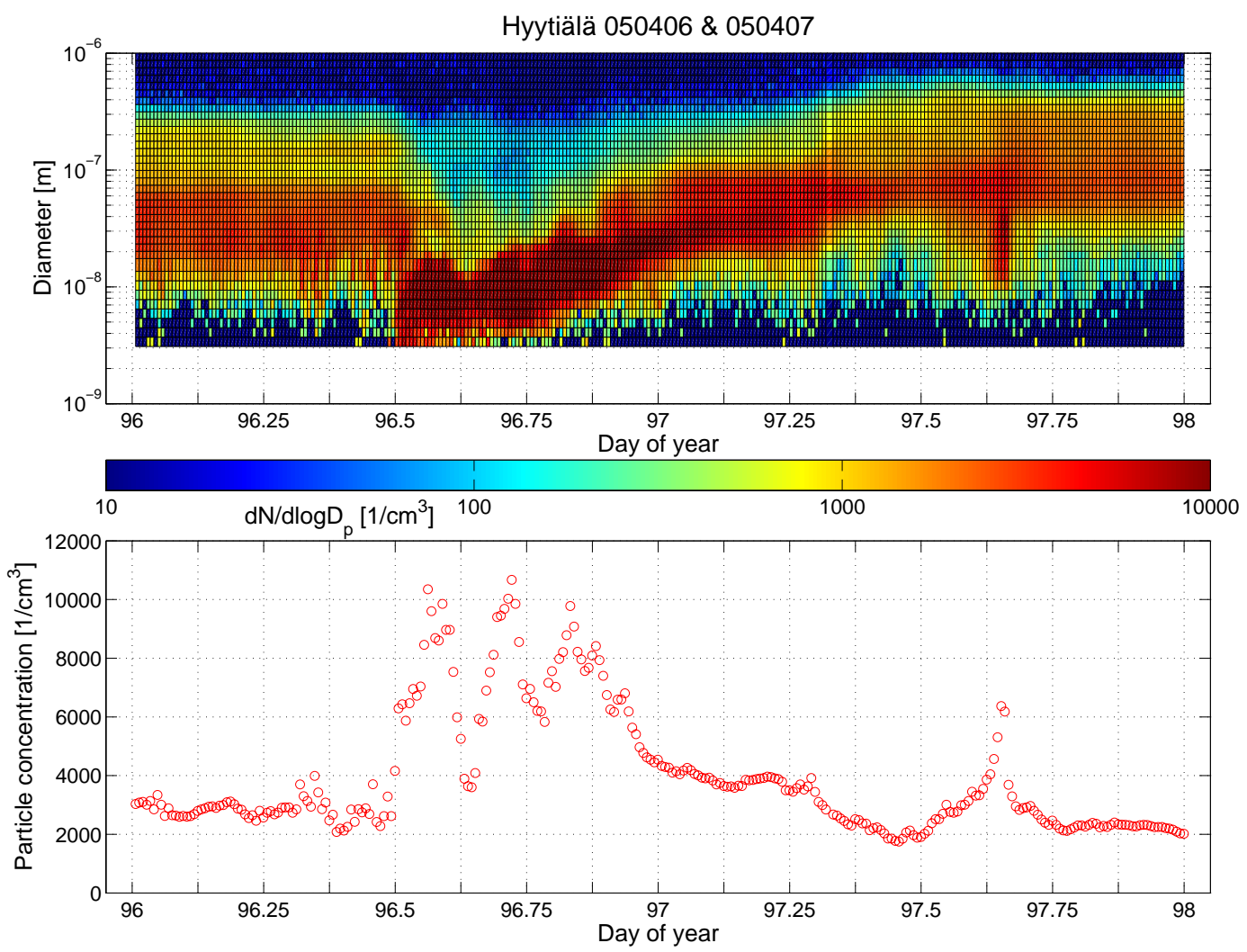

Fig. 4. Size distribution data for two consecutive days (6-7 April 2005). The top panel shows new particles forming during the first day and growing during the evening and night. At midnight the modal diameter has increased to 20-30 nm:s. Corresponding particle number concentrations are plotted in the bottom panel.

concentration around noon (Boy et al., 2005; Fiedler et al., 2005) whereas many organic compounds with low hygroscopic GF (Virkkula et al., 1999) have maxima during the night (Sellegri et al., 2005). The condensation of these gases onto the particles will alter the hygroscopicity of the particles. This effect will be strongest for small particles and less noticeable for larger ones.

The average GF was clearly lower during a night before a nucleation event for all sizes, and during the morning the GF rose quickly and reached its maximum around noon. For 20 and $30 \mathrm{~nm}$ particles, the average GF was higher during the day and following evening on event days, whereas for $50 \mathrm{~nm}$ particles it was lower. The growth factors during the following night are higher for $20 \mathrm{~nm}$, similar for $30 \mathrm{~nm}$ and smaller for $50 \mathrm{~nm}$ particles. This indicated that the effects of a nucleation event continues past midnight, and we should therefore not limit our analysis to only one day. Figure 4 constitutes a good example of an event that clearly effected the particle size distribution of the following day. The figure shows DMPS-data for the 6 and 7 April with a large amount of new particles forming during the first day. The mode of new particles grew, and only just before midnight did it reach $50 \mathrm{~nm}$.
Studying each day separately, we only had to distinguish between days with and without events. When extending our analysis to two days, the number of different possibilities doubled. The four combinations were (day 1/day 2): event/event, non-event/event, event/non-event and non-event/non-event. Figure 5 shows the corresponding analysis for $50 \mathrm{~nm}$ particles with the GF:s again averaged over three hours. Each plot in Fig. 5 is a mean of between 9 and 15 two-day periods, so the statistics are limited. Note that each day of the campaign, except the first and the last, were counted once as "day 1" and once as "day 2". The most interesting period in the figure is the time between evening of day 1 and evening of day 2 . We observed very low GF:s (below 1.18) during the previous night if day 2 was an event day (red and blue lines), independent of whether the day before was an event day or not. On the other hand, when day 2 was a non-event day, a dependency on the previous day is clear. The non-event/non-event combination (black line) can be thought of as the hygroscopic behavior of the "background" particles in the forest, increasing from about 1.22 during the night to about 1.33 during the day. The green plot corresponds to the situation shown in Fig. 4 with particles forming during day 1 and possibly reaching $50 \mathrm{~nm}$ during the evening or night. For these particles the minimum 


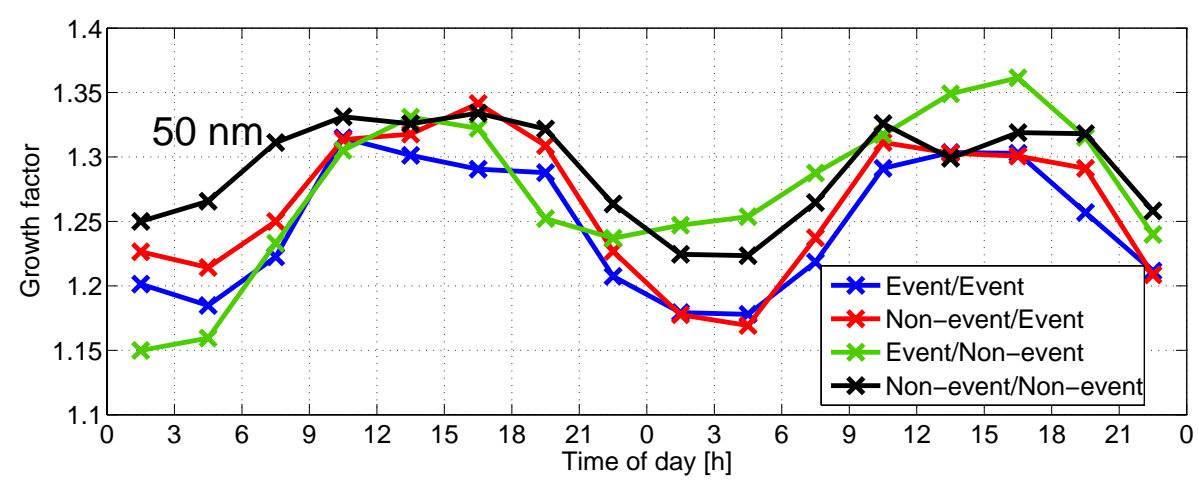

Fig. 5. The diurnal variation of the GF for $50 \mathrm{~nm}$ particles during a period of two days. The plots correspond to the four possible combinations of event days and non-event days.

occured before midnight, about six hours before all the other cases. The nightly minimum (around 1.24) and the maximum during day 2 (about 1.36) were also the highest of the four cases. The highest nightly minima for 20 and $30 \mathrm{~nm}$ particles were found during event/non-event days as well, and the day 2 maxima were very close to those during event/event days.

Event days were preceded by lower GF than non-event days. This would imply that conditions favorable for particle formation events can be seen already during the previous night and morning. The nucleating/condensing vapors might already be present and condensing on the pre-existing particles. On the other hand, low GF also means a lower condensation sink, which in turn makes nucleation more probable. The decrease in pre-existing particle area due to the observed difference in GF is, however, less than $10 \%$.

\subsection{The influence of $\mathrm{H}_{2} \mathrm{SO}_{4}$ on aerosol hygroscopicity}

The MPI in Heidelberg measured the amount of $\mathrm{H}_{2} \mathrm{SO}_{4}$ in the gas-phase during the campaign and the results were compared to the hygroscopic data measured with the HTDMA. For the comparison we discarded all $\mathrm{H}_{2} \mathrm{SO}_{4}$ data where the uncertainty limits were higher than the concentration itself, and all hygroscopicity data where the particle counts were too low for statistically reliable results. Only measurements done during the day (06:00-18:00) were included, due to the low nighttime $\mathrm{H}_{2} \mathrm{SO}_{4}$ concentrations. All $\mathrm{H}_{2} \mathrm{SO}_{4}$ measurements done within ten minutes of a HTDMA scan were averaged and compared to the measured growth factors. The results are plotted in Fig. 6. The $\mathrm{x}$-axis is logarithmic due to the large variation in $\mathrm{H}_{2} \mathrm{SO}_{4}$ concentrations (values were between $10^{5}$ and $3 \times 10^{7}$ ). Each dot corresponds to a HTDMA measurement and the red line is a linear fit to the data. Since the line is not drawn straight due to the log-linear scale, the equation for each line is written in the bottom right corner of the graphs together with the correlation coefficient $\mathrm{R}$ between $\mathrm{H}_{2} \mathrm{SO}_{4}$ concentrations and GF. Both the correlation coefficient and the steepness of the line increased when the particle size decreased. Even though the correlation was smaller for the larger sizes, when looking at $\mathrm{H}_{2} \mathrm{SO}_{4}$ concentrations above $10^{7} \mathrm{~cm}^{-3}$, the growth factors were clearly higher than on average. The correlation was statistically significant for all sizes with $p<0.00002$.

If we limited the analysis to days with new particle formation, all correlation coefficients increased, since these days usually had higher sulfuric acid concentrations than days without particle formation. The largest change was observed for $50 \mathrm{~nm}$ particles, with the correlation coefficient doubling and the steepness of the line increasing by about $60 \%$. For 20 and $30 \mathrm{~nm}$ particles, the changes were smaller, but noticeable. $10 \mathrm{~nm}$ particles were usually only observed during particle formation and therefore the changes to these particles were marginal.

$\mathrm{H}_{2} \mathrm{SO}_{4}$ has a low saturation vapor pressure and is very water soluble. The stronger effect of $\mathrm{H}_{2} \mathrm{SO}_{4}$ on small particles was to be expected since these particles had less mass and therefore small amounts of condensing vapor had a larger effect on their composition.

\subsection{Soluble fractions during particle growth}

We selected 9 days (3, 6, 12, 13, 27, 30 April and 2, 12, 13 May) with new particle formation for closer investigation. The days were chosen based on the quality of the HTDMA data and the duration of the particle formation event. Event days with unclear modes or clearly changing air masses were discarded. Contour plots of particle size distributions measured with the twin-DMPS for the selected days are shown in Fig. 7. There were clear differences between the days, both in amounts and in growth rates of the new particles.

The soluble fractions are plotted in Fig. 8. The purple curve shows the position (GMD) of the mode, and the markers the soluble fractions at that time. The different colors correspond to different dry sizes in the HTDMA, and the symbols the relative position of the mode compared to the dry size. 


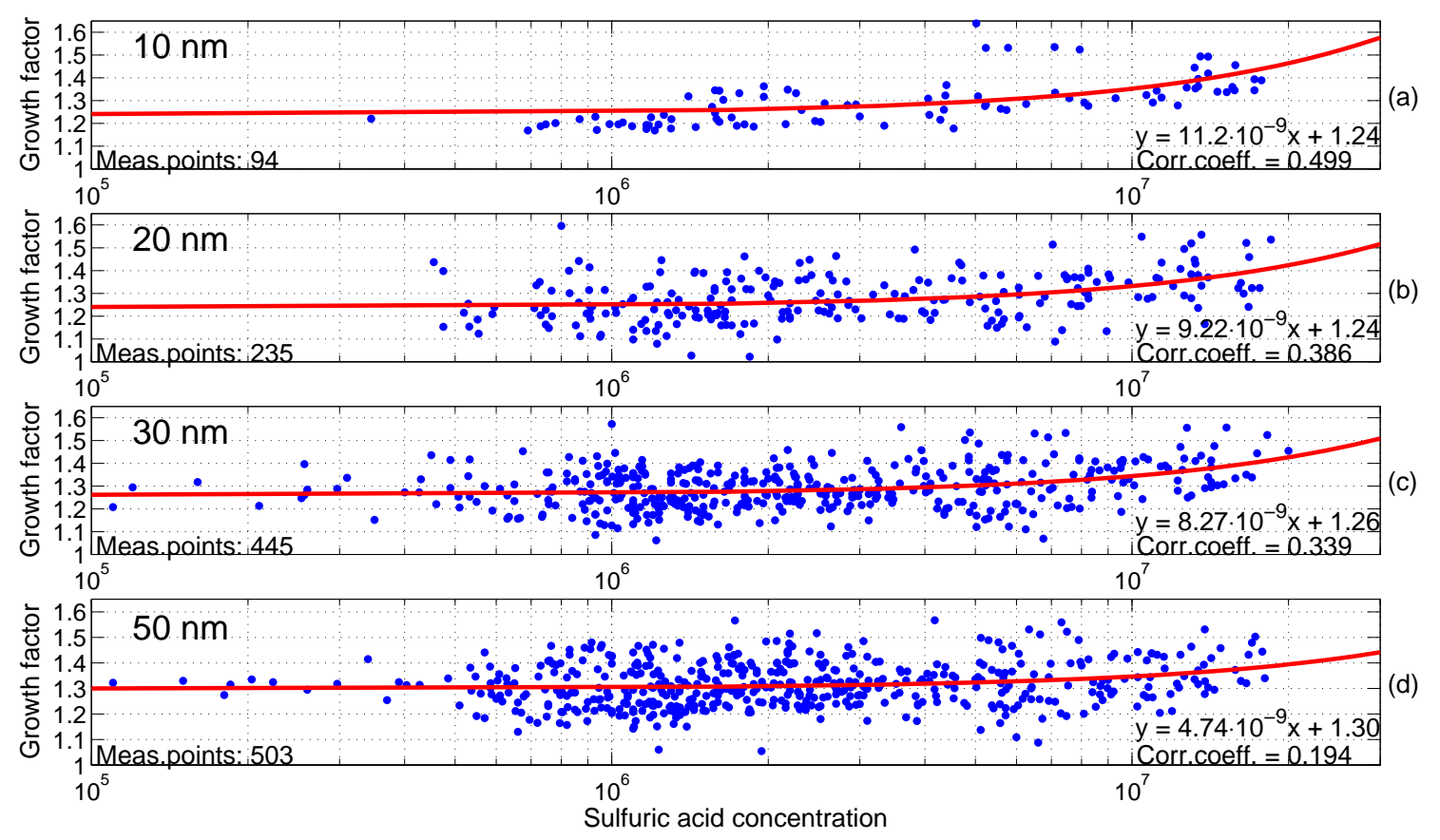

Fig. 6. Growth factor dependency on $\mathrm{H}_{2} \mathrm{SO}_{4}$ concentration. The red line is a linear fit to the data points and indicates that the $\mathrm{H}_{2} \mathrm{SO}_{4}$ concentration has a stronger effect the smaller the particles are.
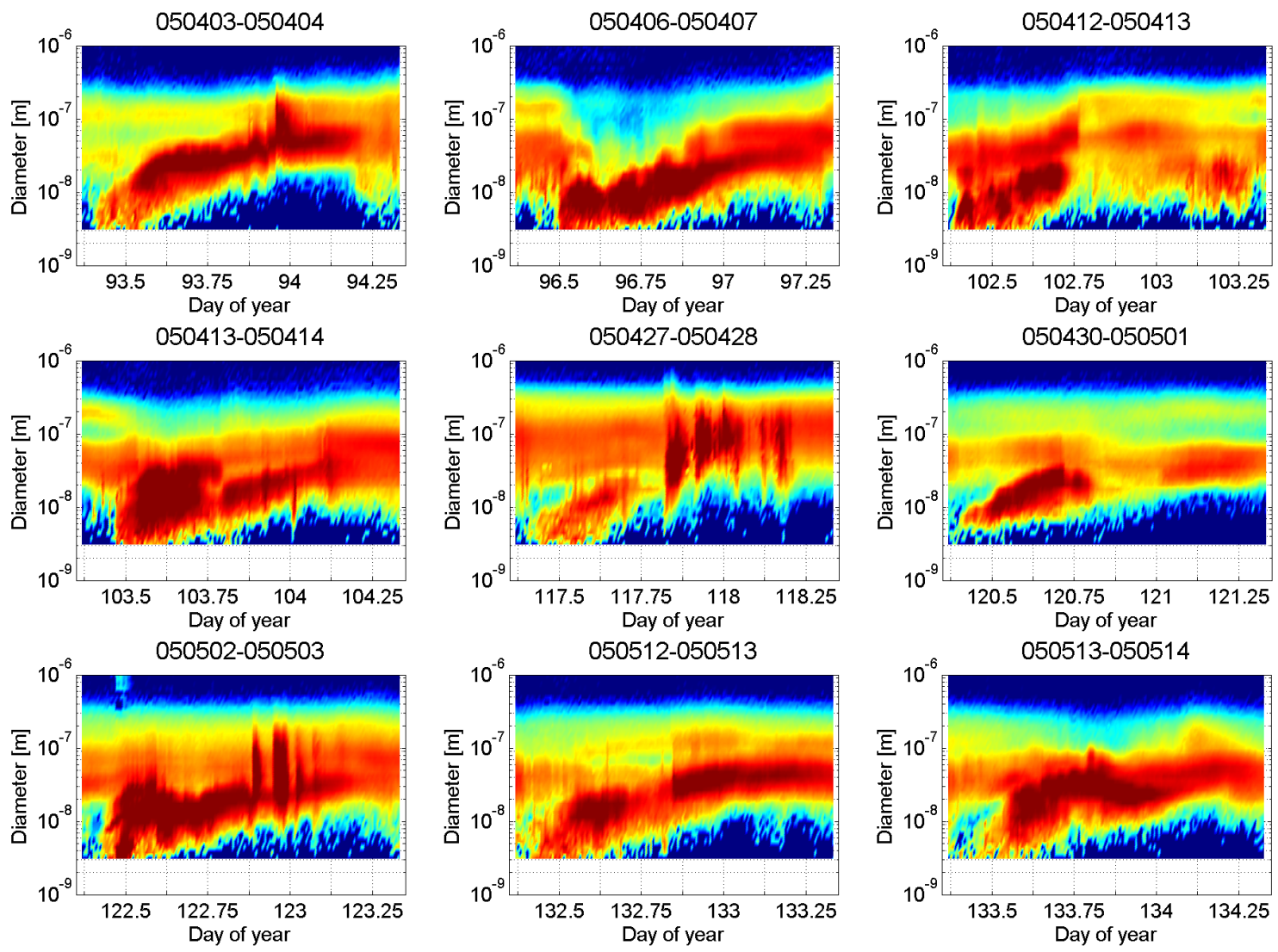

Fig. 7. Particle size distributions for 9 days with new particle formation. 

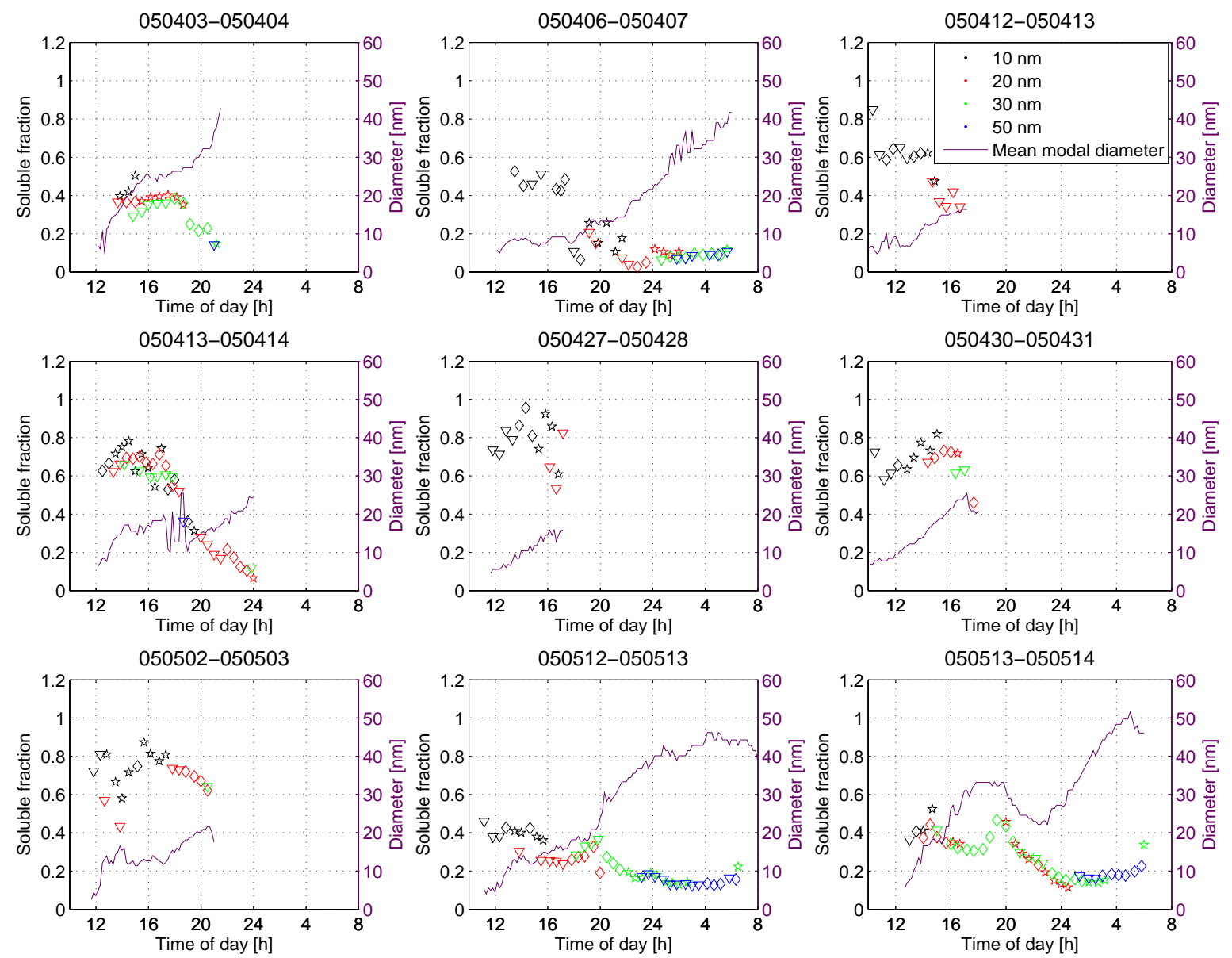

Fig. 8. Soluble fractions of particles during 9 days with particle formation. The purple line shows the center of the mode of new particles and each marker corresponds to the soluble fraction calculated from a single HTDMA scan. The color of the markers indicates the dry size in the HTDMA measurements and the shape the relative placement of the mode to the dry size. The triangles $(\Delta)$ denote $\Delta \sigma<-0.4$, the squares $(\diamond)$ that $\Delta \sigma$ is within $[-0.4,0.4]$, and the five-pointed stars $(\star)$ denote $\Delta \sigma>0.4$.

The large variation in soluble fractions between different days for $10 \mathrm{~nm}$ particles indicates that there may be very different compounds, or ratios between the compounds, involved in the initial growth of new particles. We can also note the interesting fact that events that started with particles with low $(<0.6)$ soluble fractions (3 April, 6 April, 12 May and 13 May) tended to continue for a longer time and result in larger particles than events which started with higher soluble fractions. Due to the small amount of days studied, no further going conclusions could as yet be drawn from this.

The soluble fractions were always highest for the $10 \mathrm{~nm}$ particles. The maximum soluble fraction was usually observed during the day, and after about 16:00 it started decreasing. During the days when we were able to follow the mode of new particles long enough, we saw that the soluble fraction stopped decreasing and evened out around midnight at a value around 0.1. The growth rate of the modes were far from constant, and at times the size of the modes even decreased, as seen most clearly during the last day.
For some more concrete values of the soluble fractions during different stages of particle growth, see Table 1. These are soluble fractions from the measurements closest in time to when the mode passed a dry size measured by the HTDMA. Columns 2-5 show the soluble fractions of the particle sizes during the different days with an average value calculated for each size. Dash (-) indicates that the mode never reached the specified size. The mean values clearly show how the soluble fraction decreased as the particle size increased. Columns $6-9$ give the ratio of insoluble $\left(I_{1}\right)$ to soluble $\left(I_{2}\right)$ gases condensing on the particles when growing from 10 to 20, 20 to 30 , and 30 to $50 \mathrm{~nm}$. For the growth from 10 to $20 \mathrm{~nm}$ we found values between 0.35 and 2.20 with a mean of 1.23. Earlier, Kulmala et al. (2001a) calculated values of $0.71,0.92$ and 1.4 for three case studies, which agrees with our findings. We have ignored the values from 4 April since this was an exceptional day with the growth occurring $4-8 \mathrm{~h}$ later than any other day. The average ratios $I_{1} / I_{2}$ for the growth from 20 to $30 \mathrm{~nm}$ and from 30 to $50 \mathrm{~nm}$ were 3.14 and 7.32 , respectively. 
Table 1. Soluble fractions $(\epsilon)$ and insoluble-to-soluble mass flux ratios $\left(I_{1} / I_{2}\right)$ during different stages of the particle growth. The soluble fractions usually decrease with increasing particle size due to more insoluble vapors contributing to the growth.

\begin{tabular}{rccccccc}
\hline Day & $\epsilon_{10}$ & $\epsilon_{20}$ & $\epsilon_{30}$ & $\epsilon_{50}$ & $\left(\frac{I_{1}}{I_{2}}\right)_{10 \rightarrow 20}$ & $\left(\frac{I_{1}}{I_{2}}\right)_{20 \rightarrow 30}$ & $\left(\frac{I_{1}}{I_{2}}\right)_{30 \rightarrow 50}$ \\
\hline 3.4. & 0.40 & 0.37 & 0.22 & - & 1.76 & 5.55 & - \\
6.4. & 0.06 & 0.05 & 0.08 & - & $(19.9)$ & $(9.89)$ & - \\
12.4. & 0.59 & 0.42 & - & - & 1.53 & - & - \\
13.4. & 0.67 & 0.55 & - & - & 0.89 & - & - \\
27.4. & 0.96 & 0.65 & - & - & 0.66 & - & - \\
30.4. & 0.66 & 0.73 & 0.63 & - & 0.35 & 0.70 & - \\
2.5. & 0.75 & 0.67 & - & - & 0.52 & - & - \\
12.5. & 0.43 & 0.33 & 0.24 & 0.13 & 2.20 & 3.93 & 8.43 \\
13.5. & 0.41 & 0.35 & 0.31 & 0.18 & 1.96 & 2.39 & 6.21 \\
Mean & 0.55 & 0.46 & 0.30 & 0.16 & 1.23 & 3.14 & 7.32 \\
& & & & & & &
\end{tabular}

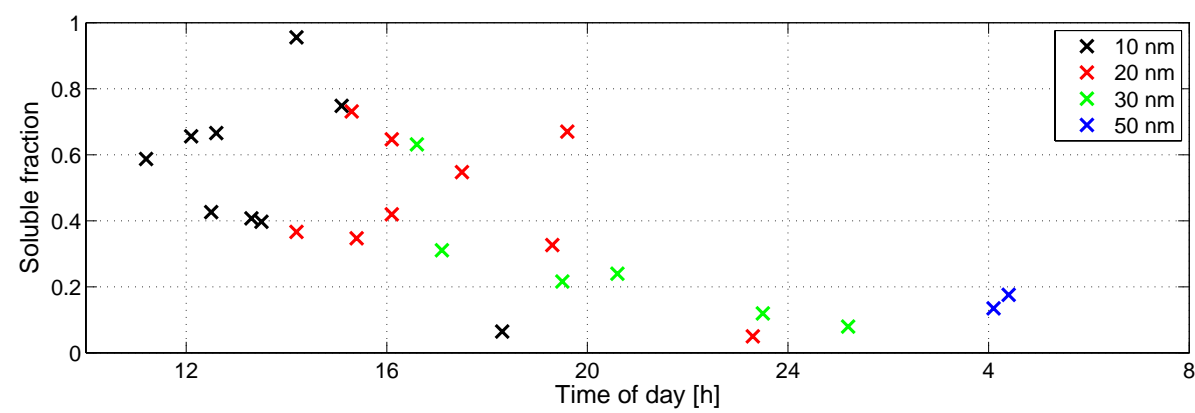

Fig. 9. Soluble fractions of new particles as a function of time. Each marker corresponds to the modes of new particles reaching $10,20,30$ or $50 \mathrm{~nm}$. The soluble fractions clearly decrease during the evening and night, showing a similar behavior as the diurnal GF variations.

The contribution of $\mathrm{H}_{2} \mathrm{SO}_{4}$ to particle growth from 10 to $20 \mathrm{~nm}$ was calculated according to Kulmala et al. (2001a). During the studied days, $\mathrm{H}_{2} \mathrm{SO}_{4}$ on average accounted for $17 \%$ (std $=11 \%$ ) of the soluble mass flux $I_{2}$. The contribution to the total growth from 10 to $20 \mathrm{~nm}$ was $8.7 \%$ which agrees well with previous measurements from Hyytiälä in 2003, when Boy et al. (2005) calculated the contribution to be $8.9 \%$ of the growth from 3 to $25 \mathrm{~nm}$. This may indicate that some additional soluble organic compounds were condensing on the particles, causing them to grow.

The decrease in soluble fractions with increase in particle size may follow from the fact that the growth to larger sizes usually happened during the evening and night. As previously mentioned this may result from the diurnal differences in the concentrations of condensable gases. The data from columns $2-5$ in Table 1 has been plotted as a function of time of day in Fig. 9. The soluble fractions of 10 and $20 \mathrm{~nm}$ particles (black and red markers) seemed independent of when the specific size was reached. The black, red and green markers that occurred the latest in Fig. 9 corresponded to 6 April and formed the exception to the previous. The $30 \mathrm{~nm}$ particles, however, had a clear dependency on the time of day, with soluble fractions decreasing with time of day.

\section{Conclusions}

A HTDMA was deployed to measure the hygroscopicity of ultra-fine particles in a boreal forest. A diurnal variation with smaller growth factors during nights was detected. The difference between night- and daytime averages was larger during days with new particle formation. The effects of a nucleation event did not end before midnight, wherefore the analysis was extended to two consecutive days. For $50 \mathrm{~nm}$ particles a non-event day showed clearly higher growth factors if the previous day had been an event day.

A correlation between the amount of $\mathrm{H}_{2} \mathrm{SO}_{4}$ and the GF was observed. This was most clear for $10 \mathrm{~nm}$ particles, for which an increase in $\mathrm{H}_{2} \mathrm{SO}_{4}$ concentration from $10^{6}$ to $10^{7}$ caused an average increase in GF of over 0.1 (from about 1.3 to 1.4).

Soluble fractions were calculated for 9 days with clear particle formation. The solubility of the mode of new particles was tracked, and was found to decrease as the particle size increased from 10 to $50 \mathrm{~nm}$. This indicated that the vapors responsible for the growth changed during the day and evening. The trend was similar to the the diurnal variation in GF for the different sized particles. Furthermore, large differences were seen in the soluble fractions of $10 \mathrm{~nm}$ particles (from 
below 0.4 to 1.0 ) which implied that the mechanism producing these particles is not always the same.

Continuous HTDMA measurements have been planned in Hyytiälä, and these measurements will give a better statistical basis for further analysis of hygroscopic properties.

Acknowledgements. We wish to thank the staff at SMEAR II and the Hyytiälä Forestry Station for their assistance throughout the campaign. This work was partly supported by the European Commission via the project "Quantification of Aerosol Nucleation in the European Boundary Layer” (QUEST) (EVK2-CT2001-00127).

Edited by: J. Abbatt

\section{References}

Aalto, P., Hämeri, K., Becker, E., Weber, R., Salm, J., Mäkelä, J. M., Hoell, C., O’Dowd, C. D., Karlsson, H., Hansson, H.C., Väkevä, M., Koponen, I. K., Buzorius, G., and Kulmala, M.: Physical characterization of aerosol particles during nucleation events, Tellus, 53B, 344-358, 2001.

Boy, M., Kulmala, M., Ruuskanen, T. M., Pihlatie, M., Reissell, A., Aalto, P. P., Keronen, P., Dal Maso, M., Hellen, H., Hakola, H., Janson, R., Hanke, M., and Arnold, F.: Sulphuric acid closure and contribution to nucleation mode particle growth, Atmos. Chem. Phys., 5, 863-878, 2005,

http://www.atmos-chem-phys.net/5/863/2005/.

Fiedler, V., Dal Maso, M., Boy, M., Aufmhoff, H., Hoffmann, J., Schuck, T., Birmili, W., Hanke, M., Uecker, J., Arnold, F., and Kulmala, M.: The contribution of sulphuric acid to atmospheric particle formation and growth: a comparison between boundary layers in Northern and Central Europe, Atmos. Chem. Phys., 5, 1773-1785, 2005, http://www.atmos-chem-phys.net/5/1773/2005/.

Hämeri, K., Väkevä, M., Aalto, P. P., Kulmala, M., Swietlicki, E., Zhou, J., Seidl, W., Becker, E., and O'Dowd, C.: Hygroscopic and $\mathrm{CCN}$ properties of aerosol particles in boreal forests, Tellus, 53B, 359-379, 2001.

Hussein, T., Dal Maso, M., Petäjä, T., Koponen, I., Paatero, P., Aalto, P., Hämeri, K., and Kulmala, M.: Evaluation of an automatic algorithm for fitting the particle number size distributions, Bor. Environ. Res., 10, 337-355, 2005.

Jokinen, V. and Mäkelä, J. M.: Closed loop arrangement with critical orifice for DMA sheath/excess flow system, J. Aerosol Sci., 28, 643-648, 1997.

Kerminen, V.-M.: The effects of particle chemical characteristics and atmosphere processes on particle hygroscopic properties, J. Aerosol Sci., 28, 121-132, 1997.

Korhonen, P., Laaksonen, A., Batris, E., and Viisanen, Y.: Thermodynamics for highly concentrated water - ammonium sulfate solutions, J. Aerosol Sci., 29, S379-S380, 1998.

Kulmala, M., Dal Maso, M., Mäkelä, J. M., Pirjola, L., Väkevä, M., Aalto, P. P., Miikkulainen, P., Hämeri, K., and O’Dowd, C. D.: On the formation, growth and composition of nucleation mode particles, Tellus B, 53, 479-490, 2001a.

Kulmala, M., Hämeri, K., Aalto, P. P., Mäkelä, J. M., Pirjola, L., Nilsson, E. D., Buzorius, G., Rannik, Ü., Dal Maso, M., Seidl, W., Hoffmann, T., Janson, R., Hansson, H.-C., Viisanen, Y.,
Laaksonen, A., and O'Dowd, C. D.: Overview of the international project on biogenic aerosol formation in the boreal forest (BIOFOR), Tellus B, 53, 324-343, 2001b.

Kulmala, M., Vehkamäki, H., Petäjä, T., Dal Maso, M., Lauri, A., Kerminen, V.-M., Birmili, W., and McMurry, P.: Formation and growth rates of ultrafine atmospheric particles: a review of observations, J. Aerosol Sci., 35, 143-176, 2004.

Mäkelä, J. M., Aalto, P., Jokinen, V., Pohja, T., Nissinen, A., Palmroth, S., Markkanen, T., Seitsonen, K., Lihavainen, H., and Kulmala, M.: Observations of ultrafine aerosol particle formation and growth in boreal forest, Geophys. Res. Lett., 24, 1219-1222, 1997.

McMurry, P. H.: The History of Condensation Nucleus Counters, Aerosol Sci. Technol., 33, 297-322, 2000.

Petäjä, T., Kerminen, V.-M., Dal Maso, M., Junninen, H., Koponen, I., Hussein, T., Aalto, P., Andronopoulos, S., Robin, D., Hämeri, K., Barzis, J., and Kulmala, M.: Sub-micron atmospheric aerosols in the surroundings of Marseille and Athens: physical characterization and new particle formation, Atmos. Chem. Phys. Discuss., 6, 8605-8647, 2006,

http://www.atmos-chem-phys-discuss.net/6/8605/2006/.

Potukuchi, S. and Wexler, A. S.: Identifying solid-aqueous phase transitions in atmospheric aerosols:I. Neutral-acidity solutions, Atmos. Environ., 29, 1663-1676, 1995.

Rader, D. J. and McMurry, P. H.: Application of the tandem differential mobility analyzer to studies of droplet growth or evaporation, J. Aerosol Sci., 28, 771-787, 1986.

Sakurai, H., Fink, M., McMurry, P., Mauldin, L., Moore, K., Smith, J., and Eisele, F.: Hygroscopicity and volatility of 4-10 nm particles during summertime, J. Geophys. Res., 110, D22S04, doi:10.1029/2005JD005918, 2005.

Sellegri, K., Umann, B., Hanke, M., and Arnold, F.: Deployment of a ground-based CIMS apparatus for the detection of organic gases in the boreal forest during the QUEST campaign, Atmos. Chem. Phys., 5, 357-372, 2005,

http://www.atmos-chem-phys.net/5/357/2005/.

Smith, J., Moore, K., McMurry, P., and Eisele, F.: Atmospheric measurements of sub-20 nm diameter particle chemical composition by Thermal Desorption Chemical Ionization Mass Spectrometry, Aerosol Sci. Technol., 38, 100-111, 2004.

Smith, J. N., Moore, K. F., Eisele, F. L., Voisin, D., Ghimire, A. K., Sakurai, H., and McMurry, P. H.: Chemical composition of atmospheric nanoparticles during nucleation events in Atlanta, J. Geophys. Res., 110, D22S03, doi:10.1029/2005JD005912, 2005.

Stolzenburg, M. R.: An ultrafine aerosol size distribution measuring system, Ph. D. Thesis, University of Minnesota, 1988.

Swietlicki, E., Zhou, J., Berg, O. H., Martinsson, B. G., Frank, G., Cederfelt, S. I., Dusek, U., Berner, A., Birmili, W., Wiedensohler, A., Yuskiewicz, B., and Bower, K. N.: A closure study of sub-micrometer aerosol particle hygroscopic behaviour, Atmos. Res., 50, 205-240, 1999.

Tang, I. N. and Munkelwitz, H. R.: Water activities, densities, and refractive indices of aqueous sulfates and sodium nitrate droplets of atmospheric importance, J. Geophys. Res., 99, 18 801-18 808, 1994.

Väkevä, M., Kulmala, M., Stratmann, F., and Hämeri, K.: Field measurements of hygroscopic properties and state of mixing of nucleation mode particles, Atmos. Chem. Phys., 2, 55-66, 2002, 
http://www.atmos-chem-phys.net/2/55/2002/.

Vesala, T., Haataja, J., Aalto, P., Altimir, N., Buzorius, G., Garam, E., Hämeri, K., Ilvesniemi, H., Jokinen, V., Keronen, P., Lahti, T., Markkanen, T., Mäkelä, J., Nikinmaa, E., Palmroth, S., Palva, L., Pohja, T., Pumpanen, J., Rannik, Ü., Siivola, E., Ylitalo, H., Hari, P., and Kulmala, M.: Long-term field measurements of atmosphere-surface interactions in boreal forest combining forest ecology, micrometeorology, aerosol physics and atmospheric chemistry, Trends in Heat, Mass \& Momentum Transfer, 4, 1735, 1998.

Virkkula, A., Van Dingenen, R., Raes, F., and Hjort, J.: Hygroscopic properties of aerosol formed by oxidation of limonene, alpha-pinene, and beta-pinene., J. Geophys. Res., 104, 35693579, 1999.
Wehner, B., Petäjä, T., Boy, M., Engler, C., Birmili, W., Tuch, T., Wiedensohler, A., and Kulmala, M.: The contribution of sulfuric acid and non-volatile compounds on the growth of freshly formed atmospheric aerosols, Geophys. Res. Lett., 32, L17 810, doi:10.1029/2005GL023827, 2005.

Winklmayr, W., Reischl, G., Lindner, A., and Berner, A.: A new electromobility spectrometer for the measurement of aerosol size distributions in the size range from 1 to $1000 \mathrm{~nm}$, J. Aerosol Sci., 22, 289-296, 1991. 